This item was submitted to Loughborough's Research Repository by the author.

Items in Figshare are protected by copyright, with all rights reserved, unless otherwise indicated.

\title{
Understanding design with VGI using an information relevance framework
}

PLEASE CITE THE PUBLISHED VERSION

http://dx.doi.org/10.1111/j.1467-9671.2012.01302.x

\section{PUBLISHER}

(c) 2012 Blackwell Publishing Ltd

\section{VERSION}

AM (Accepted Manuscript)

\section{LICENCE}

CC BY-NC-ND 4.0

\section{REPOSITORY RECORD}

Parker, Christopher J., Andrew May, and Val Mitchell. 2019. "Understanding Design with VGI Using an Information Relevance Framework”. figshare. https://hdl.handle.net/2134/10349. 
Understanding Design with VGI using an Information Relevance Framework

\author{
Christopher J. Parker ${ }^{1}$, Andrew May ${ }^{2}$, Val Mitchell ${ }^{3}$ \\ Loughborough Design School \\ Loughborough University \\ Loughborough, LE11 3TU, UK \\ +44 (0)1509 226900 \\ ${ }^{1}\left[\right.$ C.Parker] ${ }^{2}$ [A.J.May] ${ }^{3}$ [V.A.Mitchell] @lboro.ac.uk
}

\title{
SHORT TITLE:
}

Understanding VGI

\section{KEYWORDS:}

Volunteered Geographic Information, GIS, Human Factors, Design, Relevance, Risk

\section{CORRESPONDING AUTHOR:}

Christopher J. Parker, Loughborough Design School, Loughborough University, Loughborough, Leicestershire, LE11 3TU, UK. E-mail: c.parker@lboro.ac.uk 
ABSTRACT: Volunteered Geographic Information (VGI) has the potential to provide benefit to endusers over and above that of Professional Geographic Information (PGI). A multi-methods approach consisting of participatory observation, focus groups and diary studies, was used to study how VGI and PGI were actually used by a target user group. A theoretical framework of information relevance was used to understand the attributes of information that were most important in relation to the characteristics of the users' activity and their community. The key finding was that the discussion amongst GIS designers should not be whether to choose VGI or PGI as the information data set, but to consider which combination of VGI and PGI relating to different geographic features and task characteristics will best meet the users' needs. VGI is likely to be most relevant to the user when a geographic feature is dynamic rather than static in nature, and can also provide a level of detail that is unlikely to arise through PGI. These findings have implications for how different forms of information are most effective for different usage situations. Above all, a case is presented for the implementation of User Centred Design (UCD) principals when integrating VGI and PGI together in a single mashup based product. 


\section{Introduction}

The inclusion of measurements and opinions by potentially untrained amateur volunteers (Volunteered Geographic Information, VGI: Goodchild 2007a) alongside that of the trained professional (Professional Geographic Information, PGI: Parker et al. 2011) has been one of the most significant shifts in the way information delivers meaning about our environment since the birth of Web 2.0 and neogeography. Whilst in their most basic forms VGI and PGI may be similar, it is when the information describes the environment in connection with its use (rather than just presenting a collection of geographic features) when the two forms of information become distinct and characteristically different.

Elwood (2008) and Zielstra and Zipf (2010) have proposed that both VGI and PGI possess specific advantages and disadvantages for the end user, suggesting that no single information type may fulfil all of a users' requirements. Consequently, the development of interactive mashups that utilise the best aspects of VGI and PGI has great potential to enrich the user experience when interacting with Geographic Information (GI). Importantly, the work of these authors relates to the different levels of actual utility provided to the user by the information rather than the perceived utility due to the knowledge that the information is VGI or PGI. Within neogeography this is an important concept since the combination of information presented to the user may it difficult for them to distinguish between PGI and VGI.

In practice, individuals typically search for and use information. They make choices whether to accept or reject discovered sources, and derive value from information based on its relevance to the task at hand (Tóth and Tomas 2011). In the context of data quality (Coote and Rackham 2008) and User Centred Design (Preece et al. 2002), design of new systems should be based on the users' capabilities, current tasks and goals, conditions of product use and constraints on the products performance.

The aim of the study is therefore to take a user-centred approach to studying information use within a real world context, and to use a guiding theory of information relevance (outlined below) as the basis for investigating how VGI and PGI is perceived and used by the study participants. The scientific rationale for this approach is that it enables analysis of the rich detail of how information is actually used, and potential application to a wider set of usage contexts, based on identifying key characteristics of the users and their tasks, and attributes of the information used. This can lead to an understanding of the specific strengths and weakness of VGI, and how VGI and PGI may be best combined in a mashup to maximise the utility and user experience for the end user.

For purposes of the study, kayakers were selected as they (1) exhibit a wide range of skills and abilities (which impacts on information use as discussed below), (2) are widely represented in the general UK community, (3) are socially focused due to the strong social nature of VGI and (4) use a diverse range of geographically referenced information. Their activities also involve a certain level of risk, which promotes an increased amount of critical reflection during their information search (Carlson and Gieseke 1983). In addition, the kayaking activity comprises an interesting series of activities involving information, including: trip planning, the paddling activity itself (including route finding and risk analysis), and post-activity sharing of experiences. The results section outlines the main findings of this study; the discussion and conclusions sections highlight the implications in terms of more general applicability.

\section{Supporting Literature}

Possibly due to the majority of VGI research being based on Computer Science (University of Heidelberg 2010), Geography (Goodchild 2007b) and GI Science (Haklay et al. 2010, Jackson et al. 2010), many questions remain relating to the user centred impact of VGI. Although established work is valuable, it fails to consider explicitly the relationship between the characteristics of the information, how it perceived by the end user, and how it is used (and useful) to an end user. There is 
a need to understand the relative benefits of VGI and PGI from the end-users perspective (Goodchild 2008, Harding et al. 2009).

In the context of information science, the theoretical framework of relevance can be used to help understand the various qualities of both VGI and PGI in use. Saracevic (2007a, 2007b) remarked that relevance is $a$, if not even the, key notion in information science in general and information retrieval in particular. The concept of relevance can be divided into two classes: (1) objective or system-based relevance; and (2) subjective or user-based relevance (Borlund 2003). This study takes a user-based perspective, where in broad terms, relevance is a measure of the match between the information needed by a user and the information accessed - i.e. it is a user-centred 'quality' metric. It is typically a relative, rather than absolute measure, being assessed in relation to a need, rather than a benchmark value.

In a comprehensive review, Saracevic (2007a) described five key forms of relevance; system, topical, cognitive, utility and affective; this study is most closely aligned with utility relevance, where relevance describes the relation between the situation, task or problem at hand, and information objects. This is in line with the notion of situational relevance which has the following key characteristics (Borland 2003; Schamber et al 1990):

- A multidimensional concept whose meaning is largely dependent on users' perceptions of information and their own information need situations;

- A dynamic concept that depends on users' judgements of the quality of the relationship between information and information need at a certain point in time;

- A complex but systematic and measurable concept if approached conceptually and operationally from the user's perspective.

Saracevic (2007b) remarked that "relevance judgements are not completely stable; they change over time as tasks progress from one stage to another and as learning advances”. Additionally, the level of expertise of the user being investigated plays a role within relevance judgements, since higher expertise results in more discerning judgements, and higher agreement between users. Despite there being some theoretical ambiguity with the term, there is general consensus that different users use similar criteria in their judgements of information relevance, and that relevance is a useful concept across a wide range of usage situations (Saracevic 2007b). A relevance framework, which incorporates accepted relevance criteria, can therefore be used to describe and compare the relative quality of VGI and PGI, in relation to a specific usage context.

The relevance framework used within this study was that described by Barry and Schamber (1998). It is well accepted within the information science literature, and is consistent with other frameworks such as Park (1993), Cool et al. (1993) and Toms et al. (2005). This framework is shown in Table 1.

\begin{tabular}{l|l}
\hline Relevance Characteristic & Definition 'The extent to which: \\
\hline $\begin{array}{l}\text { Accessibility } \\
\text { Accuracy, validity }\end{array}$ & $\begin{array}{l}\text { some effort or cost is required to obtain information } \\
\text { information is accurate, correct or valid } \\
\text { the user exhibits an affective or emotional response to information } \\
\text { or sources of information }\end{array}$ \\
Availability of information & $\begin{array}{l}\text { sources of information are available } \\
\text { information is presented in a clear and well organised manner }\end{array}$ \\
Clarity & $\begin{array}{l}\text { information is current, recent, timely, up-to-date } \\
\text { information is in-depth or focussed, is specific to user's needs; has } \\
\text { Depth, scope, specificity }\end{array}$
\end{tabular}




\begin{tabular}{l|l}
$\begin{array}{l}\text { Quality of sources } \\
\text { Tangibility }\end{array}$ & $\begin{array}{l}\text { the information source is reputable, trusted, expert } \\
\text { information relates to real, tangible issues or hard data } \\
\text { Verification }\end{array}$ \\
$\begin{array}{l}\text { information is consistent with or supported by other information } \\
\text { within the field }\end{array}$
\end{tabular}

Table 1 - Definitions of 'relevance’ terms (Barry and Schamber 1998)

Using a relevance framework such as that shown above enables an explicit, user-centred comparison of VGI and PGI. Studies using a relevance framework have typically asked users to undertake a document search, and then rate each document against a pre-defined set of relevance criteria (e.g. Taylor et al. 2009). This research took a different approach - using relevance to understand the data that users provide when they describe how and why they use PGI and VGI within their activity. This required two key research activities: (1) development of an understanding of the information 'world' of the users of interest to enable accurate interpretation of data; (2) a means of generating broad and unbiased data that describes how information is used. These are described in the methods section that follows.

\section{Methodology}

During this study a qualitative multi-method approach was used to understand information use. Multiple methods can potentially enhance the validity of data through convergence on a truth (Erzberger and Kelle 2003, Roe 1998, Tashakkori and Teddlie 2003). As described above, methods were chosen that both developed familiarity with the domain, and promoted the generation of broad, unbiased data relating to information use - thus helping to increase the validity of the findings. Multiple methods also enabled investigation of the phases of planning and undertaking the activity.

Participatory Observation was undertaken from the position of the marginal observer (Gold 1969, Robson 2002) to (1) better understand the participants' perspective on information in use, (2) obtain an understanding of the context of the information requirements and (3) observe the impact of past experience or previously discovered information on participants. This approach provides powerful insider knowledge on the relevance of information to kayakers which may be hard to verbalise within the relative formalities of a focus group (Robson 2002). Additionally Sui and DeLyser (2011) remarked that within geography such observations allow for deeper understanding in conjunction with more robust demonstrable research methods. Observation involved engaging in weekly meetings, indoor-pool training sessions and outdoor river trips. No notes were taken during investigation due to full participation in the kayaking activities; instead observations were formally recorded postparticipation using the framework of Space, Actors, Activities, Objects, Acts, Events, Time, Goals and Feelings as recommended by Spradley (1980). Participatory observation allowed for more thorough and relevant thematic coding of the data during the analysis phase, plus a degree of validation through triangulation of multiple data sources.

Diary studies were used to help understand the trip-planning phase, and to provide a fuller picture of information use (Brookover and Back 1966, Erzberger and Kelle 2003, Preece et al. 2002). The design of the diary log sheet is based primarily on the daily record of activities by Rieman (1993), containing the time, action, location and success of the information search. Three river trips were selected through contacts within Kayak Clubs, and the trip organisers presented with diary log books. They were asked to record their information search activities on a daily basis (or as/when information searches occurred) for a period of two weeks prior to the trip. Two of these river trips also formed part of the participatory observation described above, enabling an understanding of the relevance of the information search process, the types of information obtained, and the result of this search process on the outcomes of the trip. Unfortunately the third river trip which had been planned, was cancelled due to hazardous weather during the winter of 2010. 
The final source of data was a set of semi-structured focus groups, undertaken with members of kayak clubs, sourced through purposive sampling, a process described by Morgan (1998). Participants were required to have at least two years kayaking and trip planning experience to increase the validity of the data, since those relatively more experienced can provide more discerning judgements in relation to information use (Saracevic 2007b). During the hour-long focus groups, participants were presented with a series of discussion topics including: (1) their experiences of planning and undertaking trips; (2) their understanding of VGI and PGI; and (3) instances where information had had a positive or negative impact on their activities. Sessions were recorded, transcribed in full and analysed under thematic analysis (Aronson 1994) using NVivo 9 (QSR International 2010) as a qualitative analysis tool. All references to information were coded according to (1) whether they referred to VGI or PGI, and (2) what the attributes of that information were in relation to the framework of relevance as defined by Barry and Schamber (1998); see Table 1.

The distinction between VGI and PGI is to some extent 'grey' and relatively undefined in the literature. However, within this study the distinction between VGI and PGI was as follows. PGI came from trained professionals (Fonseca and Sheth 2002), or those able to provide detailed geographic information that can be verified and integrated at the national level (Goodchild 2007b). However VGI came from those who may be considered untrained amateurs Goodchild (2007a) or have no liability or structured quality control from their efforts (Fonseca and Sheth 2002).

\section{$4 \quad$ Results}

\subsection{Participatory Observation - use of information during the activity}

Participatory observation occurred on 12 occasions, with over 100 members from independent kayaking clubs. Involvement within the kayaking activity allowed for a deeper insight into the references and terminology made during the focus groups, providing a more accurate coding of transcripts according the categories or relevance. Examples of participatory observation can be seen in Figure 1.

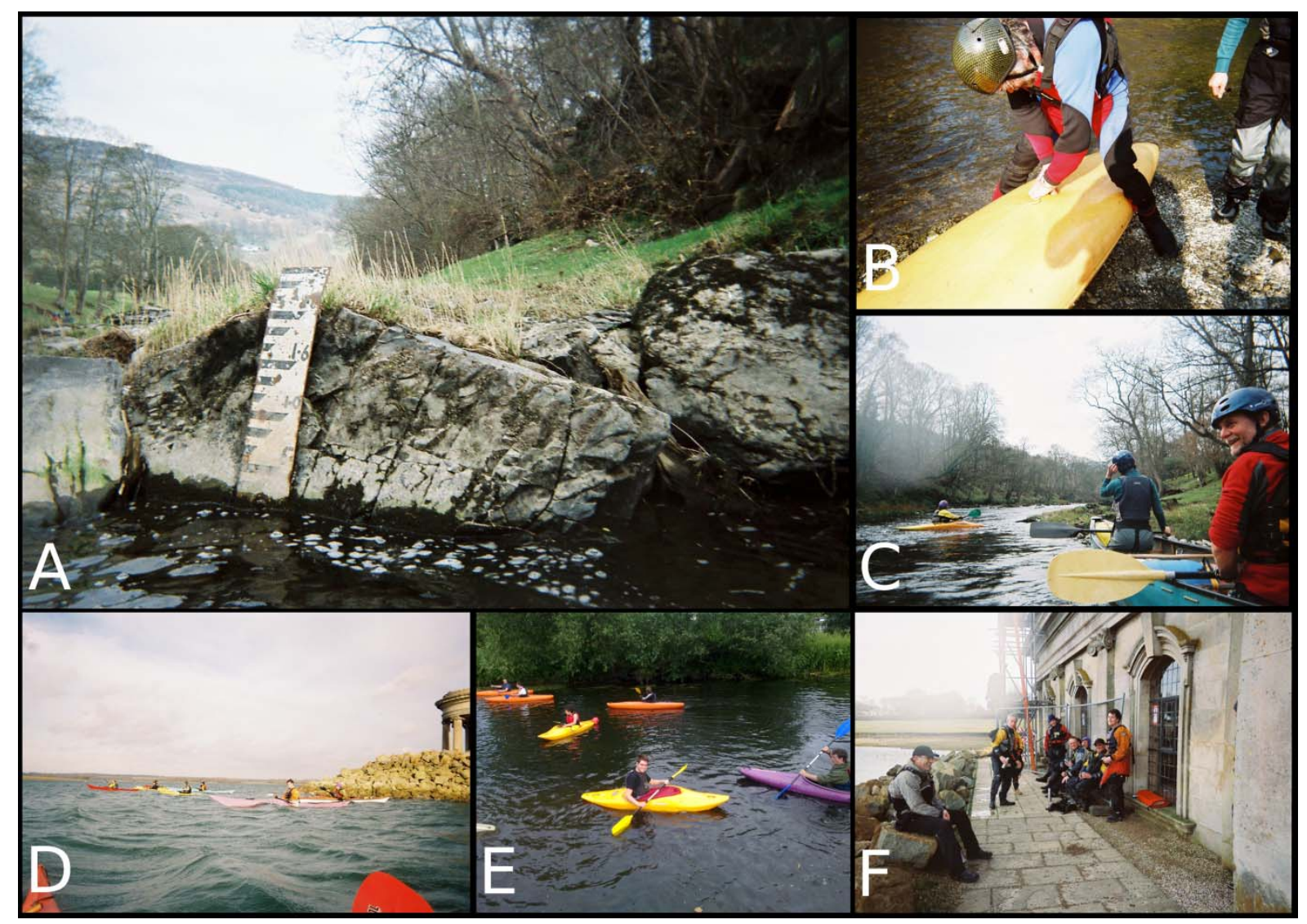


Figure 1 - Examples of Participatory Observation. A) Very low water levels not predicted by information search, B) Unpredictable events, a split in a Kayak while on river, no emergency plan, C - F) Engaging with participants during observation to understand information in use

During these sessions, there was no evidence of any consulting of reference material or official guides, suggesting that external sources of PGI and VGI were not used during the activity. This was surprising, since it was assumed that guide books and similar would be used while paddling. However, it was clear that environmental information cues, such as river levels and potential obstructions were actively sought, the main objective being the effective management (as opposed to minimising) of risk. These environmental cues clearly satisfy several of the relevance criteria in Table 1 , including accuracy, currency, and tangibility. In addition, verification was also important, where multiple cues (e.g. relating to presence of obstructions) were sought. The role of experience of fellow paddlers was also key, in terms of the search for, and interpretation of, external environmental cues.

\subsection{Diary Studies - use of information for trip planning}

Information accessed by the trip organisers centred on websites containing PGI (e.g. weather sites, official water records, etc.) and forums containing VGI data about specific locations (e.g. river reports, club websites, etc.). The searches for information were limited to those which the participant deemed as directly related to the activity rather than generic information websites. These included a mix of both VGI and PGI sources. The search of information sources was limited to those judged to have a high quality of source (Table 1), with an emphasis on VGI coming from within the wider kayaking community. Both PGI and VGI were predominantly used to make predictions about outdoor conditions, and were searched for close to the time of departure. The dynamic nature of information assessment was also apparent, as differences between the predicted and observed conditions served to lower the perception of the quality of source used.

\subsection{Focus Groups - detailed comparison of VGI and PGI}

Thirty two participants took part in four focus group sessions, each lasting approximately one hour. During the focus groups PGI sources mentioned included guide books, maps and official reports, with VGI focusing mainly on forums, amateur reports and social media. A detailed coding of the focus group including the number of references made to each theme and the number of participants who mentioned that theme enabled an investigation of the relative importance of the information relevance attributes and a comparison between VGI and PGI; see Table 2 and Table 3 below. Note that the salience of specific attributes is being used as a surrogate for their relative importance. It is assumed that those attributes of information that are most important would also be those which are mentioned, particularly when probes based on 'why?' are used as prompts throughout the focus groups. 


\begin{tabular}{|c|c|c|c|c|}
\hline Relevance Theme & Sub Category & Themes From Data & VGI & PGI \\
\hline \multirow[t]{3}{*}{ Accessibility } & Negative & Costs money to aquire & 0 & 5 \\
\hline & Positive & Easy to access & 2 & 2 \\
\hline & & Free to get hold of & 4 & 0 \\
\hline \multirow[t]{2}{*}{ Accuracy } & Positive & Acurate & 7 & 5 \\
\hline & & Less biased & 1 & 0 \\
\hline \multirow[t]{2}{*}{ Affectiveness } & Negative & unfriendly sources & 5 & 0 \\
\hline & & Friendly sources & 4 & 0 \\
\hline Availability of Information & Positive & Large volume of info available & 2 & 0 \\
\hline \multirow[t]{2}{*}{ Clarity } & Negative & Sometimes Vague & 1 & $\overline{9}$ \\
\hline & Positive & Well structured & 0 & 5 \\
\hline \multirow[t]{2}{*}{ Currency } & Negative & Out of date & 3 & 17 \\
\hline & Positive & Up to date & 16 & 2 \\
\hline \multirow[t]{3}{*}{ Depth, Scope, Specificty } & Negative & Incomplete & 4 & 11 \\
\hline & Positive & multiple sources converge on truth & 6 & 3 \\
\hline & & Unique Information & 2 & 1 \\
\hline \multirow[t]{5}{*}{ Quality of Sources } & Negative & Opinionated & 11 & $\overline{13}$ \\
\hline & & Puropseful Misinformation & 7 & 0 \\
\hline & & Unreliable or incorrect & 14 & 4 \\
\hline & Positive & Reliable & 11 & 19 \\
\hline & & Trust personal contacts the most & 9 & 0 \\
\hline \multirow[t]{2}{*}{ Tangibility } & High Tangibility & & 7 & 8 \\
\hline & Low Tangibility & & 20 & 20 \\
\hline \multirow[t]{2}{*}{ Verification } & Negative & not as good as experience & 1 & 1 \\
\hline & Positive & The best form of information & 2 & 0 \\
\hline
\end{tabular}

Table 2 - Information characteristics results - cases coded 


\begin{tabular}{|c|c|c|c|c|}
\hline Relevance Theme & Sub Category & Themes From Data & VGI & PGI \\
\hline \multirow[t]{3}{*}{ Accessibility } & Negative & Costs money to aquire & 0 & 6 \\
\hline & Positive & Easy to access & 3 & 4 \\
\hline & & Free to get hold of & 5 & 0 \\
\hline \multirow[t]{2}{*}{ Accuracy } & Positive & Acurate & 15 & 5 \\
\hline & & Less biased & 1 & 0 \\
\hline \multirow[t]{2}{*}{ Affectiveness } & Negative & unfriendly sources & 6 & 0 \\
\hline & & Friendly sources & 5 & 0 \\
\hline Availability of Information & Positive & Large volume of info available & 3 & 0 \\
\hline \multirow[t]{2}{*}{ Clarity } & Negative & Sometimes Vague & 1 & 12 \\
\hline & Positive & Well structured & 0 & 8 \\
\hline \multirow[t]{2}{*}{ Currency } & Negative & Out of date & 4 & 30 \\
\hline & Positive & Up to date & 23 & 2 \\
\hline \multirow[t]{3}{*}{ Depth, Scope, Specificty } & Negative & Incomplete & 8 & 22 \\
\hline & Positive & multiple sources converge on truth & 11 & 8 \\
\hline & & Unique Information & 2 & 1 \\
\hline \multirow[t]{5}{*}{ Quality of Sources } & Negative & Opinionated & 26 & 22 \\
\hline & & Puropseful Misinformation & 8 & 0 \\
\hline & & Unreliable or incorrect & 18 & 5 \\
\hline & Positive & Reliable & 28 & 33 \\
\hline & & Trust personal contacts the most & 18 & 0 \\
\hline \multirow[t]{2}{*}{ Tangibility } & High Tangibility & & 14 & 9 \\
\hline & Low Tangibility & & 44 & 40 \\
\hline \multirow[t]{2}{*}{ Verification } & Negative & not as good as experience & 1 & 1 \\
\hline & Positive & The best form of information & 4 & 0 \\
\hline
\end{tabular}

Table 3 - Information characteristics results - coding references

This study identified accuracy, clarity, currency, depth \& scope and quality of information sources as being those of highest relevance to the participants within this study. Note that the tables above only summarise the data from the focus groups. Table 4 below summarises the main findings from the focus groups in relation to the information relevance framework of Barry and Schamber (1998). Quotes from participants are included to exemplify key points, and are referenced to participants thus: $[\mathrm{xx}]$.

\begin{tabular}{|c|c|c|}
\hline $\begin{array}{l}\text { Relevance } \\
\text { Attribute }\end{array}$ & Outcomes & Example Quotations \\
\hline Accessibility & $\begin{array}{l}\text { - Cost of PGI being an inconvenience rather } \\
\text { than a factor preventing acquisition of } \\
\text { information } \\
\text { - } \quad \text { VGI was easy to access } \\
\text { - VGI being free }\end{array}$ & $\begin{array}{l}\text { Quality of [PGI] varies a lot and you need to pay } \\
\text { before you see what you get [\#2-3-09] } \\
\text { People don't generally want money for [VGI] } \\
\text { [\#2-3-09] }\end{array}$ \\
\hline $\begin{array}{l}\text { Accuracy, } \\
\text { validity }\end{array}$ & 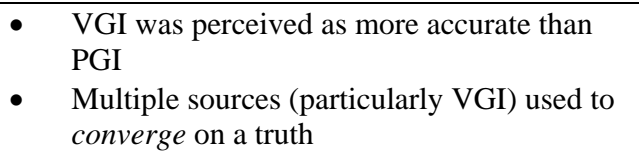 & $\begin{array}{l}\text { [it is] easier to judge the difficulty [of the river] } \\
\text { due to [VGI's] better opinions \& more detail } \\
\text { [\#2-1-02] }\end{array}$ \\
\hline Affectiveness & $\begin{array}{l}\text { - Low prominence given to VGI exhibiting } \\
\text { affectiveness, with little impact on users’ } \\
\text { desire to use VGI }\end{array}$ & $\begin{array}{l}\text { Even farmers say: "look guys; if you go down } \\
\text { that track you have a better access to the water" } \\
{[\# 2-4-03]}\end{array}$ \\
\hline $\begin{array}{l}\text { Availability of } \\
\text { information }\end{array}$ & $\begin{array}{l}\text { Little comment on the quantity of VGI } \\
\text { available } \\
\text { No comment about PGI availability, even } \\
\text { though PGI is highly visible in the UK } \\
\text { (Ordnance Survey 2010) }\end{array}$ & $\begin{array}{l}\text { It's free and there's lots of it. Everybody has } \\
\text { their own opinions about it, which means there's } \\
\text { a lot of opinions and you don't know if that is } \\
\text { right [\#2-4-04] }\end{array}$ \\
\hline
\end{tabular}




\begin{tabular}{|c|c|c|}
\hline Clarity & $\begin{array}{l}\text { PGI was sometimes vague and hard to } \\
\text { understand } \\
\text { - } \quad \text { VGI offers clarity to a degree that is not } \\
\text { offered by PGI }\end{array}$ & $\begin{array}{l}\text { If you're reading it out of a book you might not } \\
\text { quite understand certain aspects [\#2-3-06] } \\
\text { [VGI is] often produced in a more usable format } \\
\text { and more accessible [format. You're] not } \\
\text { trawling through information on forums [\#2-4- } \\
\text { 05] }\end{array}$ \\
\hline Currency & $\begin{array}{l}\text { - } \quad \text { PGI tends to be out of date } \\
\text { - } \quad \text { VGI is more up to date and better at } \\
\text { reflecting current conditions }\end{array}$ & $\begin{array}{l}\text { What maps and guidebooks don't give you is up } \\
\text { to date information. Just because it was a good } \\
\text { guide to the river five years ago doesn't mean } \\
\text { it's a good guide to the river now [\#2-1-05] } \\
\text { [VGI is] often more accurate with [the inclusion } \\
\text { of] real time information [\#2-1-02] }\end{array}$ \\
\hline $\begin{array}{l}\text { Depth, scope, } \\
\text { specificity }\end{array}$ & $\begin{array}{ll}\text { - } & \text { PGI is seen as more incomplete than VGI } \\
\text { - } & \text { PGI can describe the general terrain better } \\
\text { - } & \text { VGI can describe specific details better } \\
\text { - } & \text { Better to use multiple sources }\end{array}$ & $\begin{array}{l}\text { Like we said with maps, you can't gauge, ... bank } \\
\text { levels, ...it's, there more for distances and } \\
\text { everything like that [\#2-1-08] } \\
\text { I think you use it, all these little bits of } \\
\text { information to build a whole picture of what you } \\
\text { want to do [\#2-1-04] }\end{array}$ \\
\hline $\begin{array}{l}\text { Quality of } \\
\text { sources }\end{array}$ & $\begin{array}{ll}\text { - } & \text { Both PGI and VGI are opinionated } \\
\text { - } & \text { Homogenous sources provide better } \\
\text { information } \\
\text { - } & \text { General level of distrust in the quality of } \\
& \text { VGI } \\
\text { - } & \text { PGI is seen as more reliable than VGI } \\
\end{array}$ & $\begin{array}{l}\text { Locals will probably know more about access, } \\
\text { but locals are often not kayakers [\#2-1-07] } \\
\text { [PGI is] usually [a] very trustworthy source with } \\
\text { high level of experience [\#2-4-01] }\end{array}$ \\
\hline Tangibility & $\begin{array}{ll}- & \text { Responses related to low tangibility } \\
\text { outcomes }\end{array}$ & $\begin{array}{l}\text { I think... local knowledge is better than the } \\
\text { [professional information]" [\#2-1-08] }\end{array}$ \\
\hline Verification & $\begin{array}{l}\text { VGI and PGI are no substitute for } \\
\text { experience; the best form of information }\end{array}$ & $\begin{array}{l}\text { I think people that have done the river before are } \\
\text { the best people to talk to. They know your level } \\
\text { of paddling ability and if they think 'oh no, it's } \\
\text { not for you', they'll say 'it's a great river... but I } \\
\text { don't think you're at that level yet' [\#2-1-08] }\end{array}$ \\
\hline
\end{tabular}

Table 4 - Main findings from the focus groups

\section{Discussion}

The analysis of VGI and PGI according to the relevance framework of Barry and Schamber (1998) has shown some clear differences in the perception of these information sources by end-users. This study showed that PGI has a lower degree of perceived overall depth about specific locations than VGI, but a great degree of overall scope and consistency of coverage. The participatory observation showed that when the users talked about VGI sources, the topics covered were also of greater diversity than their PGI counterparts. Consequently, PGI provides information on the general, wide reaching topography, while VGI provides detail about specific locations, sometimes in much greater detail, but with patchy coverage. Levitin and Redman (1995) suggest that scope and the level of detail are important dimensions of data quality, which alongside price and value is one of the key criteria for product selection (Zeithaml 1988). Quality judgements in relation to information-based products are therefore important in terms of their adoption by potential consumers.

VGI sources were preferred in situations where the geographic features being described altered regularly (e.g. water levels); in contrast, PGI was preferred when describing relatively static geography (e.g. topography). These findings are in agreement with Nolan (1976) and Schuett (1993) who commented that information received from informal sources is the most informative due to its ability to reflect changes in the environment. 
This is not just due to the volunteered nature of the information, but critically, is also influenced by the channels through which VGI tends to be communicated. Information collected and distributed through regularly updated, interactive channels (rather than through the slower traditional mediums such as print with longer refresh cycles) has a higher chance of reflecting current conditions and satisfying the currency requirement within the relevance framework of Barry and Schamber (1998). The finding that VGI is best suited for fast changing geography that may be hard to capture through traditional mediums is directly in line with the concepts outlined by Goodchild (2007a) when he defined the term Volunteered Geographic Information.

The comments of the participants suggest that VGI possesses a higher level of clarity than PGI. This concept of users finding higher degrees of clarity within data provided by other similar (homogenous) contributors is in line with Parker et al. (2010). Whilst investigating the various users involved in VGI, Parker et al. (2010) noted that members of specific user groups are more likely to use information provided by their own user group than that contributed by outsiders, even though this 'outsider' information may actually be equally useful. Of particular interest are the remarks of Schuett (1993) that within situations of risk, information from within the user community is particularly valued. Rogers (2003), in a broader context, also demonstrated that the more homogenous two individuals are, the easier it is for ideas and information to be shared between them. In this study, kayakers understood kayakers, and in a wider context of use this study demonstrates how the relevance of VGI may be linked to the homogeneity of the contributor and user.

Although the completeness of individual information sources was of importance for participants within this study, the diary studies in particular highlighted how for many of the issues faced in planning, multiple information sources were used to meet the needs of the user - verification was important. Individual PGI sources were more often described as accurate than VGI sources; more VGI sources were used in the 'convergence of truth' than PGI sources. This is in line with the information interaction perspective of Hertzum et al. (2002) - in order to achieve a level of confidence an information seeker is comfortable with, they must collect multiple sources of information to counteract the limitations of individual pieces of information. The higher the risk (in the broad sense of the term) of the activity, the more important this issue appears to be. Barry and Schamber (1998) remarked that conditions of use incorporating high rates of change (e.g. the weather) resulted in higher perceived significance of information verification. Although not represented within Tables 1 and 2, this element of verification is present in the use of multiple information sources to converge on a truth. Finally, Bishr and Janowicz (2010) also commented that as long as a proxy for establishing trust in VGI is put in place, the multiple combination of information has great potential for realising the concept of a fully integrated digital earth.

Although VGI is often distributed under a Creative Commons licence and is therefore free to access (Goodchild 2008), this does not make it appear more appealing to the user; or to make PGI comparatively less attractive. The diary studies showed that participants used whichever information source they felt most likely to solve their information needs; be it either free or at cost. This may be explained by the work of Richins and Bloch (1986) who asserted that the higher the perceived risk, the higher the involvement in the information search. This would suggest that individuals are more willing to spend resources (effort and/or money) for information if there is risk associated with an activity. As Borlund (2003) commented: "the relevance of a document should be judged on the basis of its content rather than its physical properties, such as physical availability or monetary cost", which would explain this use of PGI. The finding that participants would pay for information if it was seen as appropriate and useful is interesting, partly due to the fact that proponents of VGI hold the free nature of their information up as a key reason why VGI is better and more appropriate for general use than PGI (Flanagin and Metzger 2008, Parker et al. 2010). Consequently there may be an inverse relationship between an activity's risk and importance of the accessibility attribute (including the free nature of VGI).

Participatory observation highlighted how before, during and after kayaking sessions club members would share experiences, contacts and sources with each other while talking about trips they wished 
to plan and undertake. This demonstrates how through formal and informal means VGI is created, yet the lack of comment on this during the focus groups demonstrates how the participants did not see this information sharing as an explicit activity. This highlights the need to find new ways of encouraging users to contribute, otherwise VGI will not fulfil its potential

The main limitation of the study is the issue of generalising these research findings from kayakers to a wider audience. Kayakers were used solely as an example of a single demographic that was necessary in order to study situated use of information sources. Kayakers and the kayaking task can be characterised in terms of social groups seeking information in order to plan and undertake an activity where outcomes matter. In addition, both micro and macro levels of geographic information are highly relevant. These characteristics are seen in a wide range of information seeking activities, where it is important to maximise the relevance of information available to end users. In addition, a theoretical framework was employed that focuses on the core qualities of information - i.e. this framework is user-task and information-source agnostic and has been applied widely in a range of application domains (Saracevic 2007b). The data from the study relate to kayakers, since they were the subject of study. However, the findings are applicable to multiple instances of information use that share the characteristics described above.

\section{Conclusions}

The aim of this study was to use a user-centred approach, and an information relevance theoretical framework, to investigate how VGI and PGI are used within a situation where information 'matters'. Relevance, comprising specific attributes, has been a useful concept for comparing the relative qualities of PGI and VGI in relation to the needs of the end user.

VGI was shown to possess specific advantages to the user community. It is easy to access while offering a wide spatial coverage of potentially up-to-date information on geographic regions important to the disseminating community. Although it can be influenced by subjective interpretation from contributors (as well as potential purposeful misinformation) it was generally considered reliable and relevant by participants, particularly when it came from within the user community. Additionally in some cases it was seen as more accurate than PGI with a higher degree of clarity and specific detail. It was also able to react to dynamic changes in the environment or other important factors (e.g. weather conditions).

The verification of VGI, and the quality of the source, are critical issues that influence the extent to which VGI is deemed relevant by a user group. Verification can be achieved by reference to multiple sources that 'converge on the truth'. Quality of source comes from knowing (and understanding the significance of) the credentials of the contributor. As an information source, participants felt a surprisingly low level of affection towards it, and although there was a large quantity of VGI available, users still perceived it to have limited availability. Additionally, while the detail of VGI relating to specific geographic features was relatively high, its overall geographic coverage was poorer than that of PGI.

The study suggests great potential for VGI to counteract the shortcomings of PGI sources in relation to the needs of the user. The integration of these two forms of data within a 'mashup' could combine the structure, consistency and source quality of PGI with the currency and intuitive appeal of VGI. Such mashups would have higher personal relevance (Table 1) than could be achieved by either VGI or PGI alone.

A theoretical framework was used to analyse information use within this study. This allows the findings to be generalised to a wide range of situations where geographic information is being used by individuals, and where outcomes 'matter'. This paper builds on the noted differences between VGI and PGI in use, and consequently supports the view that the best way to provide advantage to a user is through combining both forms of information, to deliver a best of both worlds situation. However, as this paper has shown, the best of both worlds depends on user judgements rather than purely on 
objective geographic truth. Consequently in order to produce highly satisfying, enjoyable and functional products combining VGI and PGI a user centred design perspective should be taken that takes into account the end users, their activities, their context, and the attributes of information that are of critical importance.

\section{References}

Aronson J 1994 A pragmatic view of thematic analysis. The Qualitative Report 2(1): 1-3

Barry C L and Schamber L 1998 Users' criteria for relevance evaluation: a cross-situational comparison. Information Processing and Management 34(2/3): 219-236

Bishr M and Janowicz K 2010 Can we Trust Information? - The Case of Volunteered Geographic Information. In Towards Digital Earth: Search, Discover and Share Geospatial Data, Berlin, Germany

Borlund P 2003 The Concept of Relevance in IR. Journal of the American Society for Information Science and Technology 54(10): 913-925

Brookover L and Back K W 1966 Time Sampling as a Field Technique. Human Organization 25(1): 64-70

Carlson J A and Gieseke R J 1983 Price search in a product market. Journal of Consumer Research 9(4): 357-365

Cool C, Belkin N J, Frieder O and Kantor P 1993 Characteristics of text affecting relevance judgements. In Proceedings of the 14th National Online Meeting,

Coote A and Rackham L 2008 Neogeography Data Quality - is it an issue? In Proceedings of AGI Geocommunity '08, Stratford-Upon-Avon, UK

Elwood S 2008 Volunteered geographic information: future research directions motivated by critical, participatory, and feminist GIS. GeoJournal 72: 173-183

Erzberger C and Kelle U 2003 Making Inferences in Mixed Methods: The Rules of Integration. In Tashakkori A and Teddlie C (eds) Handbook of Mixed Methods in Social \& Behavioral Research. Sage Publications, USA: 457-488

Flanagin A J and Metzger M J 2008 The credibility of volunteered geographic information. GeoJournal 72: 137-148

Fonseca F and Sheth A 2002 The Geospatial Semantic Web. WWW document, http://www.ucgis.org/priorities/research/2002researchPDF/shortterm/e_geosemantic_web.pdf

Gold R L 1969 Roles in Sociological field observation. In McCall G J and Simmons J L (eds) Issues in Participant Observation: a text and reader. Addison-Wesley, USA: 30-38

Goodchild M F 2008 Commentary: Whither VGI? GeoJournal 72(3): 239-244

Goodchild M F 2007a Citizens as Sensors: The world of Volunteered Geography. GeoJournal 69(4): 211-221 
Goodchild M F 2007b Citizens as Voluntary Sensors: Spatial Data Infrastructure in the World of Web 2.0. International Journal of Spatial Data Infrastructure Research 2: 24-32

Haklay M, Ather A and Basiouka S 2010 How Many Volunteers Does It Take to Map An Area Well? In Proceedings of the GIS Research UK 18th Annual Conference,

Harding J, Sharples S, Haklay M, Burnett G, Dadashi Y, Forrest D, Maguire M, Parker C J and Ratcliff L 2009 Usable geographic information - what does it mean to users? In Proceedings of the AGI GeoCommunity '09 Conference, Stratford-Upon-Avon, UK

Hertzum M, Andersen H H K, Andersen V and Hansen C B 2002 Trust in Information Sources: Seeking Information from People, Documents, and Virtual Agents. Interacting with Computers 14: $575-599$

Jackson M J, Rahemtulla H and Morley J 2010 The Synergistic Use of Authenticated and CrowdSourced Data for Emergency Response. In Proc. 2nd Int. Workshop on Validation of GeoInformation Products for Crisis Management (VALGEO),

Levitin A and Redman T 1995 Quality dimensions of a conceptual view. Information Processing and Management 31(1): 81-88

Morgan D L 1998 Planning Focus Groups . USA, SAGE Publications, inc.

Nolan S D 1976 Tourists' use and evaluation of travel information sources: Summary and conclusions. Journal of Travel Research 14(3): 6

Ordnance Survey 2010, Annual Report and Accounts 2009-10, Ordnance Survey, London, United Kingdom

Park T K 1993 The nature of relevance in information retrieval: An empirical study. Library Quarterly 63(3): 318-351

Parker C J, May A J and Mitchell V 2011 Relevance of Volunteered Geographic Information In A Real World Context. In Proceedings of GIS Research UK 19th Annual Conference,

Parker C J, May A J and Mitchell V 2010 An Exploration of Volunteered Geographic Information Stakeholders. In Proceedings of the GIS Research UK 18th Annual Conference, London, UK

Preece J, Rogers Y and Sharpe H 2002 Interaction Design: beyond human-computer interaction . United States of America, John Wiley \& Sons

QSR International 2010 NVivo 9. Melbourne, Australia: QSR International.

Richins M L and Bloch P H 1986 After the New Wears off: The Temporal Context of Product Involvement. The Journal of Consumer Research 13(2): 280-285

Rieman J 1993 The diary study: a workplace-oriented research tool to guide laboratory efforts. In Proceedings of the INTERACT '93 and CHI '93 conference on Human factors in computing systems, Amsterdam, The Netherlands

Robson C 2002 Real World Research (Second edition). Oxford, UK, Blackwell Publishing 
Roe E 1998 Taking Complexity Seriously: Policy Analysis, Triangulation and Sustainable Development . USA, Kluwer Academic Publishers

Rogers E M 2003 Diffusion of Innovations (Fifth edition). USA, Free Press

Saracevic T 2007a Relevance: A Review of the Literature and a Framework for Thinking on the Notion in Information Science. Part II: Nature and Manifestations of Relevance. Journal of the American Society For Information Science and Technology 58(13): 1915-1933

Saracevic T 2007b Relevance: A Review of the Literature and a Framework for Thinking on the Notion in Information Science. Part III: Behavior and Effects of Relevance. Journal of the American Society For Information Science and Technology 58(13): 2126-2144

Schuett M A 1993 Information sources and risk recreation: The case of whitewater kayakers. Journal of Park and Recreation Administration 11(1): 67-77

Spradley J P 1980 Participant Observation . New York, USA, Holt, Rinehart \& Winston

Sui D and DeLyser D 2011 Crossing the qualitative-quantitative chasm I: Hybrid geographies, the spatial turn, and volunteered geographic information (VGI). Progress in Human Geography February(28th): 1-14

Tashakkori A and Teddlie C 2003 Handbook of Mixed Methods in Social \& Behavioral Research . USA, Sage Publications

Taylor A, Zhang X and Amadio W J 2009 Examination of the Relevance Criteria Choices and the Information Search Process. Journal of Documentation 65(5): 719-744

Toms E G, O'Brian H L, Kopak R and Freund L 2005 Searching for relevance in the relevance of search. In Proceedings of Fourth International Conference on Conceptions of Library and Information Science (CoLIS 2005), University of Strathclyde, Glasgow

Tóth K and Tomas R 2011 Quality Of Geographic Information - Simple Concept Made Complex By The Context. In Proceedings of the 25th International Cartographic Conference and the 15th General Assembly of the International Cartographic Association,

University of Heidelberg 2010 OpenRouteService. WWW document, http://129.206.229.146/openrouteservice/?lang=en\#

Zeithaml V A 1988 Consumer perceptions of price, quality, and value: a means-end model and synthesis of evidence. The Journal of Marketing 52(3): 2-22

Zielstra D and Zipf A 2010 A Comparative Study of Proprietary Geodata and Volunteered Geographic Information for Germany. In Geospatial Thinking: Proceedings of the 13th AGILE International Conference on Geographic Information Science, Guimarães, Portugal 